\title{
Comparison of the Hamstring Muscle Length and Sciatic Nerve Tension among Computer Workers with Different Subtypes of Lower Back Pain
}

\author{
Min-HeE KIM ${ }^{1)}$, Won-GYU YoO ${ }^{2)}$ \\ 1) Institute of Health Science, Yonsei University \\ 2) Department of Physical Therapy, College of Biomedical Science and Engineering, Inje University \& \\ Elderly Life Redesign Institute: 607 Obangdong, Gimhae, Gyeongsangnam-do, 621-749 Republic of \\ Korea.TEL: +82-55-320-3994, FAX:+82-55-329-1678,E-mail:won7y@inje.ac.kr
}

\begin{abstract}
Purpose] This study compared the hamstring length and sciatic nerve tension between a healthy group and two homogeneous lower back pain (LBP) subgroups. [Subjects] The subjects were office workers who were recruited from the local community: 16 healthy subjects without LBP, and 31 subjects with current LBP. [Methods] The active knee extension (AKE) test was conducted to evaluate hamstring muscle length. The modified straight leg raise (SLR) test was performed to test for sciatic nerve irritation in the LBP patients. The significance of differences in the AKE and modified SLR tests among the three groups was analyzed using one-way ANOVA. [Result] The hamstring muscle length in LBP subgroup with lumbar flexion rotation syndrome was significantly longer than that in the healthy group. The sciatic nerve tension in the LBP subgroup with lumbar flexion rotation syndrome was significantly greater than that in the healthy group. [Conclusion] This study showed that the hamstring muscle length and sciatic nerve tension differed with subtypes of LBP.

Key words: Hamstring muscle length, Sciatic nerve tension, Low back pain
\end{abstract}

(This article was submitted Feb. 29, 2012, and was accepted Apr. 11, 2012)

\section{INTRODUCTION}

Recently, the relationship between low back pain (LBP) and prolonged posture has been established, because LBP increases among computer workers who sit for most of the day ${ }^{1)}$. Sitting for long periods places a high load on the lumbopelvic region, reducing the circulation of blood in the lower extremities, and may result in either muscle shortening or muscle weakness, or hyper- or hypo-mobility of the joints ${ }^{2}$. The mechanical properties of tissues around the lumbopelvic region, i.e. muscle length or nerve tension, affect lumbopelvic motion and contribute to LBP. Many clinical researchers have suggested that the shortening of the hamstring muscles may affect static or dynamic postures of the pelvis and lumbar spine ${ }^{3,4)}$. Increased sciatic nerve tension may also limit lumbar or hip motion'5). Many researchers have provided information on categorizing LBP into more homogeneous subtypes for a heterogeneous LBP. The movement system impairment classification system of a number of systems is based on the kinesiopathological approach $^{6,7)}$. The movement system impairment classification for LBP categorizes different subtypes through examination of movement directions and reported symptoms associated with LBP. To assess movement patterns of LBP subtypes, based on the movement system impairment classification system, can be meaningful ${ }^{6}$. Therefore, the purpose of this study was to compare the hamstring length and sciatic nerve tension between healthy group and two homogeneous
LBP subgroups.

\section{SUBJECTS AND METHODS}

The subjects were recruited from the local community. They were office workers who sat for more than four hours a day at work. First, the subjects were divided into with or without LBP groups and then each subject with LBP was examined and classified into two subgroups based on a clinical examination. The subjects were divided into three groups. Sixteen people with no history of LBP were recruited as the control group (Group 1). For this investigation, two LBP subtypes of the movement system impairment classification system, the lumbar flexion rotation syndrome (Group 2) and the lumbar extension rotation syndrome (Group 3), were selected because these two subtypes were reported to be more prevalent in previous studies ${ }^{8}$. The seventeen subjects in the Group 2 had a tendency to show rotation and flexion movement of the lumbar spine. This tendency arises or increases with prolonged sitting and with forward bending or twisting movements associated with rotation and flexion of the lumbar spine. The fourteen subjects in the Group 3 tended to move the lumbar spine in the direction associated with rotation and extension during trunk and lower extremity movements. Signs are decreased when the lumbar rotation and extension movement is restricted and corrected ${ }^{6}$. The subjects' general characteristics were: average age 23.8 years, average height 
$169.1 \mathrm{~cm}$, and average weight $61.3 \mathrm{~kg}$ in Group 1; average age 23.5 years, average height $173.3 \mathrm{~cm}$, and average weight $67.2 \mathrm{~kg}$ in Group 2; were average age 23.8 years, average height $169.4 \mathrm{~cm}$, and average weight $65.0 \mathrm{~kg}$ in Group 3.

The active knee extension (AKE) test was conducted to evaluate the hamstring muscle length of the dominant lower $\operatorname{limb}^{9)}$. A pressure biofeedback unit was used to prevent compensated movement of the lumbopelvic region. Each subject was placed in the supine position, and the pressure biofeedback unit was placed between the examination bed and the subject's lumbopelvic region (L4-S1). The measured leg was then flexed at 90 degrees at the hip and knee on an adjustable support table, and the contralateral leg was fixed to the bed with a strap across the thigh. In this position, the plastic bag of the biofeedback unit was inflated to a pressure of $40 \mathrm{mmHg}$. A ruler with an inclinometer was attached to the line between the lateral femoral epicondyle and the lateral malleolus and adjusted to 0 degrees in the testing position and then extend the lower leg while relaxing their ankle. The AKE was performed until the subject could feel resistance in the stretched hamstring muscle. At that point, the hamstring muscle length was indicated by the AKE angle measured by the digital inclinometer. The AKE angle was defined as the angle of knee extension.

The straight leg raise (SLR) has been used to test sciatic nerve irritation of the dominant lower limb in patients with $\mathrm{LBP}^{10)}$. The SLR with 15 to 20 degrees of ankle dorsiflexion, a modification of the SLR, has been used to measure sciatic nerve tension regardless of hamstring muscle length ${ }^{5)}$. We performed the SLR and the modified SLR to test sciatic nerve tension using a digital inclinometer to measure sciatic nerve tension. The subjects were instructed to lie supine with both legs straight, and then the examiner attached the ruler with the inclinometer the lower leg of the subject along the line between the lateral femoral epicondyle and the lateral malleolus. After the inclinometer was adjusted to 0 degrees, the test was performed. First, the straight leg angle was recorded when the SLR was performed with the ankle in the relaxed position (SLR angle). Then, the modified SLR was performed while maintaining 15 degrees of ankle dorsiflexion, and the angle was measured (modified SLR angle). During the tests, the angle of the hip, knee, and ankle were visually monitored. If the hip rotated externally, the knee flexed, or the ankle was in flexion plantar, the test was considered a failure. The sciatic nerve tension was expressed as $\mathrm{SLR}_{\text {sciatic }}$ angle. The $\mathrm{SLR}_{\text {sciatic }}$ angle was calculated as follows: SLR $_{\text {sciatic }}$ angle $=$ SLR angle - modified SLR angle.

The SPSS statistical package was used to analyze the significance of differences in the AKE and modified SLR tests. The significance of accepted for values of differences among the 3 groups were tested by a one-way ANOVA, with statistical significance $p<0.05$. Multiple comparisons were based on Tukey's correction.

\section{RESULTS}

The hamstring muscle length was measured using the AKE test and was expressed as the AKE angle. The AKE angles were Group 1, $48.9 \pm 9.7$ degrees; Group 2, $40.7 \pm$
Table 1. Comparison of the AKE angle and $\mathrm{SLR}_{\text {sciatic }}$ angle among the three groups

\begin{tabular}{lrcc}
\hline \multirow{2}{*}{ Angles } & \multicolumn{3}{c}{ Mean \pm SD (degrees) } \\
\cline { 2 - 4 } & Group 1 & Group 2 & Group 3 \\
\hline AKE & $48.9 \pm 9.7$ & $40.7 \pm 7.6^{*}$ & $47.3 \pm 10.3$ \\
SLR $_{\text {sciatic }}$ & $6.9 \pm 3.0$ & $10.5 \pm 3.6^{*}$ & $9.1 \pm 5.4$ \\
\hline
\end{tabular}

$* \mathrm{p}<0.05$

7.6 degrees; and Group 3, $47.3 \pm 10.3$ degrees. The AKE angle was significantly smaller in Group 2 than in Group $1(p<0.05)($ Table 1$)$. The degree of sciatic nerve tension was expressed in terms of the $\mathrm{SLR}_{\text {sciatic }}$ angle. The $\mathrm{SLR}_{\text {sciatic }}$ angles were Group 1, $6.9 \pm 3.0$ degrees; Group 2, $10.5 \pm 3.6$ degrees; and Group 3, $9.1 \pm 5.4$ degrees. The sciatic nerve tension was significantly greater in Group 2 than in Group 1 $(\mathrm{p}<0.05)$ (Table 1).

\section{DISCUSSION}

This study investigated the differences in hamstring muscle length and sciatic nerve tension between a group of healthy subjects and two homogeneous groups of subjects with LBP. Pearcy et al. ${ }^{11)}$ reported in a radiographic study that the hamstring muscle length affected the lumbopelvic region and LBP. Gajdosik et al. ${ }^{12)}$ also reported that hamstring shortening was associated with limitation of lumbar spine flexion contributing to LBP. A shortened hamstring muscle would pull the ischial tuberosity in the inferior direction during forward bending, and as a result, would reduce the anterior tilting motion of the pelvis ${ }^{12}$. In our study, hamstring muscle length was significantly shorter in Group 2 than in Group 1. Tightness in the posterior thigh caused by an increase in sciatic nerve tension may also reduce hip motion ${ }^{5,6}$. Increased sciatic nerve tension has been shown to cause ischemia and hypoxia in nerve tissue or reduce axoplasmic flow, which can induce microtrauma in an adjacent muscle ${ }^{13}$. In our study, the sciatic nerve tension was significantly greater in Group 2 than in Group 1. However, Group 3 showed no significant differences in either hamstring length or sciatic nerve tension. Turl and George $^{14)}$ reported that increased neural tension in the sciatic nerve may contribute to hamstring stiffness and tightness in the posterior leg. Additionally, increased sciatic nerve tension contributes to decreased stretch tolerance of the hamstring muscle.

Based on the results of our study, we consider that the hamstring muscle length and sciatic nerve tension have higher correlation with lumbar flexion rotation LBP syndrome than lumbar extension rotation LBP syndrome. The results of this study showed that the characteristics of the different subtypes of LBP differed. The absence of specific objective diagnostic examinations for mechanical LBP makes a specific therapeutic approach difficult. Therefore, this study is fairly meaningful because it attempted to cluster specifically classified subgroups of LBP patients. We suggest that stretching exercises for the hamstring muscle 
and releasing exercises for sciatic nerve tension would be more effective for the treatment of lumbar flexion rotation LBP syndrome than in people with lumbar extension rotation LBP syndrome. Future studies will need to look for sensitive diagnostic characteristics between asymptomatic and LBP persons, or between various subtypes of LBP.

\section{ACKNOWLEDGEMENTS}

This work was supported by the 2012 Inje University research grant.

\section{REFERENCES}

1) Van Dillen LR, Gombatto SP, Collins DR, et al.: Symmetry of timing of hip and lumbopelvic rotation motion in 2 different subgroups of people with low back pain. Arch Phys Med Rehabil, 2007, 88: 351-360. [Medline] [CrossRef]

2) Valachi B, Valachi K: Mechanisms leading to musculoskeletal disorders in dentistry. J Am Dent Assoc, 2003, 134: 1344-1350. [Medline]

3) Halbertsma JP, Goeken LN, Hof AL, et al.: Extensibility and stiffness of the hamstrings in patients with nonspecific low back pain. Arch Phys Med Rehabil, 2001, 82: 232-238. [Medline] [CrossRef]

4) Whitehead CL, Hillman SJ, Richardson AM, et al.: The effect of simulated hamstring shortening on gait in normal subjects. Gait Posture, 2007, 26 :
90-96. [Medline] [CrossRef]

5) Coppieters MW, Alshami AM, Babri AS, et al.: Strain and excursion of the sciatic, tibial, and plantar nerves during a modified straight leg raising test. J Orthop Res, 2006, 24: 1883-1889. [Medline] [CrossRef]

6) Sahrmann S: Diagnosis and treatment of movement impairment syndromes. New York, USA: Mosby, 2002.

7) O'Sullivan P: Diagnosis and classification of chronic low back pain disorders: maladaptive movement and motor control impairments as underlying mechanism. Man Ther, 2005, 10: 242-255. [Medline] [CrossRef]

8) Wand BM, Hunter R, O'Connell NE, et al.: The self-reported aggravating activities of people with chronic non-specific low back pain do not involve consistent directions of spinal movement: an observational study. Aust J Physiother, 2009, 55: 47-51. [Medline] [CrossRef]

9) Rakos DM, Shaw KA, Fedor RL, et al.: Interrater reliability of the activeknee-extension test for hamstring length in school-aged children. Pediatr Phys Ther, 2001, 13: 37-41. [Medline] [CrossRef]

10) Rebain R, Baxter GD, McDonough S: A systematic review of the passive straight leg raising test as a diagnostic aid for low back pain (1989 to 2000). Spine (Phila Pa 1976), 2002, 27: E388-E395.

11) Pearcy M, Portek I, Shepherd J: The effect of low-back pain on lumbar spinal movements measured by three-dimensional X-ray analysis. Spine, 1985, 10: 150-153. [Medline] [CrossRef]

12) Gajdosik RL, Albert CR, Mitman JJ: Influence of hamstring length on the standing position and flexion range of motion of the pelvic angle, lumbar angle, and thoracic angle. J Orthop Sports Phys Ther, 1994, 20: 213-219. [Medline]

13) Shacklock M: Neurodynamics. Physiotherapy, 1995, 81:9-16. [CrossRef]

14) Turl SE, George KP: Adverse neural tension: a factor in repetitive hamsrting strain? J Orthop Sports Phys Ther, 1998, 27: 16-21. [Medline] 